\title{
Pulmonary Vascular Response to Aerosolized Cromolyn Sodium and Repeated Epochs of Isocapneic Alveolar Hypoxia in Lambs
}

\author{
BONNIE J. TAYLOR, JAMES E. FEWELL, AND GREGORY L. KEARNS
}

Perinatal Research Laboratory, Departments of Pediatrics, Physiology, and Pharmaceutics, University of Arkansas for Medical Sciences, Little Rock, Arkansas 72205

\begin{abstract}
We investigated the effect of aerosolized cromolyn sodium (CS) on the pulmonary vascular response to isocapneic alveolar hypoxia in chronically instrumented lambs aged 11-12 days. Each lamb underwent two operations: chest instrumentation for measurements of pulmonary arterial, systemic arterial, and left atrial pressures, and pulmonary blood flow; and a tracheotomy for drug administration. The animals were recovered 3 days before study. Each lamb received an aerosol of normal saline (placebo) and CS in paired experiments $24 \mathrm{~h}$ apart. In the first set of experiments $(n=8)$, placebo or CS $(30 \mathrm{mg})$ was given, followed by four 15-min epochs of alveolar hypoxia $\left(8 \% \mathrm{O}_{2}, 5 \% \mathrm{CO}_{2}, 87 \% \mathrm{~N}_{2}\right)$ each separated by 30 min of alveolar normoxia $\left(21 \% \mathrm{O}_{2}\right)$. During hypoxia after both placebo and CS, pulmonary arterial pressure and resistance increased. This response was unchanged with repeated epochs. In the second set of experiments $(n=8)$, normal saline or CS (30 mg) was administered three times over a 90-min period, followed by one 15-min epoch of hypoxia. Pulmonary arterial pressure and resistance increased during hypoxia after placebo, but did not change after CS. Thus, the single dose of aerosolized CS did not alter the pulmonary vascular response to alveolar hypoxia, whereas the triple dose of $\mathrm{CS}$ attenuated the response. Additionally, the pulmonary vascular response to hypoxia alone was not altered by repeated exposures to hypoxia. We conclude that CS interferes with the mechanism(s) responsible for hypoxic pulmonary vasoconstriction in newborn lambs. (Pediatr Res 23: 513-518, 1988)
\end{abstract}

\section{Abbreviations}

HPV, hypoxic pulmonary vasoconstriction CS, cromolyn sodium

Alveolar hypoxia elicits pulmonary vasoconstriction by mechanisms which remain unknown $(1,2)$. HPV does not require systemic humoral or neural input and is therefore intrinsic to the lung, but varies widely between species $(1,2)$. Elaboration of chemical mediators after degranulation of pulmonary mast cells during hypoxia has been implicated as a possible etiology for the pulmonary vasoconstriction observed in rats (3) and sheep (4).

Received July 24, 1987; accepted January 12, 1988.

Correspondence and reprint requests Bonnie J. Taylor, M.D., Department of Pediatrics, Slot 512, University of Arkansas for Medical Sciences, 4301 W. Markham Street, Little Rock, AR 72205.

Supported by a Grant-In-Aid to B.J.T. from the Arkansas Affiliate of the American Heart Association. J.E.F. is an Established Investigator of the American Heart Association.
Other studies have refuted the importance of mast cells in the pulmonary pressor response to hypoxia in cats (5), mast celldeficient mice (6), and rats (7). Despite these interspecies differences, a contributing role for mast cells in HPV remains an attractive hypothesis because of the strategic perivascular location of these calls in the lung $(3,4,8)$, and the variety of vasoactive mediators contained within them (9).

$\mathrm{CS}$ is a known inhibitor of mast cell degranulation and when administered intravenously, has been shown to inhibit or modify HPV in adult sheep (4), dogs $(10,11)$, and newborn lambs (12). Administration of CS by aerosolization directly into the airways would provide an alternative route of delivery and might offer a more efficient means of locally depositing the drug. Partial blockade of HPV has been demonstrated in adult sheep after treatment with aerosolized CS (13). The purpose herein was to investigate the effect of aerosolized CS on the pulmonary vascular response to repeated epochs of isocapneic alveolar hypoxia in newborn lambs.

\section{METHODS}

Sixteen lambs ( $4.6 \pm 1.3 \mathrm{~kg}), 11-12$ days of age, were used for these experiments. Each lamb was separated from its ewe at 3 days of age in preparation for surgery and housed in a plexiglass cage $(3 \times 4 \mathrm{ft})$ with continuous access to an artificial lamb's milk diet (Lamb Milk Replacer, Land O'Lakes, Inc., Fort Dodge, IA). The animals were allowed to acclimate to the laboratory environment before surgery. Animals of both sexes were used and all were feeding well, gaining weight, and had normal physical examinations and rectal temperatures at the time of study.

Each lamb underwent two operations before study. For surgery, each animal was given atropine sulfate $(0.05 \mathrm{mg} / \mathrm{kg}$ subcutaneously) and the trachea was intubated with a cuffed endotracheal tube. Anesthesia was maintained by ventilating the lungs with $2.0-3.0 \%$ isoflurane (Forane) in oxygen and nitrous oxide (3:1). Each animal's electrocardiogram and rectal temperature were monitored during surgery and body temperature was maintained near $39^{\circ} \mathrm{C}$ with a heating pad.

The first operation was done at 8 days of age. A midline sternotomy was performed to expose the heart and great vessels. The pericardium was incised and a precalibrated electromagnetic flow transducer (SP 7515, ID 9.0-10.0 mm, Gould-Statham, Inc., Oxnard, CA) was placed around the main pulmonary artery to measure pulmonary blood flow. Polyvinyl chloride catheters treated with TDMAC heparin complex (5\%) (Polysciences Inc., Warrington, PA) were inserted into the main pulmonary artery (distal to the flow transducer), ascending aorta, and right and left atrial appendages to measure pulmonary and systemic arterial and left atrial pressures. The right atrial catheter was used to infuse fluids during surgery. All catheters and the flow transducer cable were tunneled subcutaneously and were exteriorized on 
the lamb's back. A daily intramuscular dose of procaine penicillin $\mathrm{G}(100,000 \mathrm{U} / \mathrm{kg})$ and gentamicin sulfate $(2 \mathrm{mg} / \mathrm{kg})$ was administered before surgery and each day postoperatively. Buprenorphine hydrochloride (Buprenex) $(0.01 \mathrm{mg} / \mathrm{kg})$ was administered intramuscularly as an analgesic every $12 \mathrm{~h}$ postoperatively if needed for pain. Animals generally required only one dose and were routinely active and eating within $12 \mathrm{~h}$ of surgery. No analgesia was administered within $24 \mathrm{~h}$ of an experiment.

The second operation was done at 10 days of age and consisted of a tracheotomy for placement of a fenestrated tracheostomy tube (Shiley Inc., Irvine, CA). We chose to separate the surgical procedures because of an observed increase in morbidity (atelectasis, respiratory distress) when the sternotomy and tracheotomy were performed at the same time. The tracheostomy tube allowed the animal to breathe through the opening of the tube only (cuff inflated, inner cannula in place) or entirely through its upper airway (cuff inflated, decannulation cannula in place). After surgery, the decannulation cannula was inserted into the tracheostomy tube so that air flow during tidal respiration was through the upper airway. The animals were recovered an additional 24 $h$ after this procedure before they were studied.

For study, each animal was secured in a sling and placed in a soundproof chamber with light and temperature control. The vascular catheters were connected to strain gauge manometers (Statham P23ID) using rigid pressure monitoring tubing. The height of the manometers was adjusted to place them at the level of the heart and the flow transducer cable was connected to a flow meter (Statham SP 2202). During a study, pulmonary blood flow, and pulmonary and systemic arterial and left atrial pressures were monitored continuously on a Grass model 7 polygraph recorder (Grass Medical Instruments, Quincy, MA). Zero references of hemodynamic measurements were made before the start of each experiment, then repeated once during the experiment and once at the conclusion of the study. The flow transducer output was adjusted so that end-diastolic flow was at zero. This position was checked before each measurement of pulmonary blood flow. Pulmonary vascular resistance was calculated as the difference between the mean pulmonary artery pressure and mean left atrial pressure divided by the pulmonary blood flow (corrected for body weight). Systemic vascular resistance was calculated in a similar manner: mean systemic arterial pressure divided by pulmonary blood flow.

Eight lambs were studied in the first set of experiments designed to determine 1 ) whether the pulmonary vascular response to alveolar hypoxia is altered by pretreatment with one dose of aerosolized CS and 2) if the pulmonary vascular response to hypoxia is altered over time with repeated exposure to hypoxia. After baseline cardiovascular measurements were made, the inner cannula was inserted into the tracheostomy tube and attached via a T-piece to an ultrasonic nebulizer (Pulmosonics, DeVilbiss Co., Somerset PA). A single aerosol treatment using CS (30 mg) (Intal $10 \mathrm{mg} / \mathrm{ml}$, Fison's Corp., Bedford, MA) or an equal volume of normal saline $(0.9 \%$ ) was administered over a 10 -min period. The inner cannula was removed and the decannulation tube was reinserted into the tracheostomy so that the lamb could breathe through its upper airway. After a 15-min recovery period, hypoxia was introduced by flowing a gas mixture of $8 \% \mathrm{O}_{2}, 5 \%$ $\mathrm{CO}_{2}$, and $87 \% \mathrm{~N}_{2}$ into a bag placed over the animal's head and secured to a gas-tight fit. The fraction of inspired oxygen was measured using an oxygen analyzer (model 0250, Salter Instrumentation, Arvin, CA) positioned inside the bag at the level of the animal's snout. End-tidal $\mathrm{CO}_{2}$ was not measured in all animals, but was checked during several studies using a medical gas analyzer (LB-2; SensorMedics, Anaheim, CA) positioned inside the bag. Flow rates necessary to achieve this mixture varied slightly from animal to animal, but usually required 4.0-4.5 liter $/ \mathrm{min} 12 \% \mathrm{O}_{2}, 5 \% \mathrm{CO}_{2}$, and $1.5 \mathrm{liter} / \mathrm{min} \mathrm{N}_{2}$. After $15 \mathrm{~min}$ of hypoxia, the gas mixture was switched to $21 \% \mathrm{O}_{2}$ and the animal was allowed to recover for $30 \mathrm{~min}$. A second epoch of hypoxia was induced in the same manner, followed by a $30-\mathrm{min}$ recovery period. A total of four epochs of alveolar hypoxia were studied in each animal. Cardiovascular measurements were recorded $15 \mathrm{~min}$ after the aerosol treatment, at the end of each epoch of hypoxia, and after each recovery period. Arterial blood gas samples were drawn from the systemic arterial catheter at baseline, 15 min after the aerosol delivery, after $15 \mathrm{~min}$ of hypoxia, and after $30 \mathrm{~min}$ of recovery. Each animal was studied twice; once after an aerosol of normal saline (placebo) and once after an aerosol of CS. These paired experiments were separated by $24 \mathrm{~h}$ and the sequence of placebo and CS was alternated between animals.

Eight animals were studied in the second set of experiments designed to determine whether the pulmonary vascular response to hypoxia is altered by pretreatment with three consecutive aerosol doses of CS. After baseline measurements were made, three $30 \mathrm{mg}$ aerosol treatments of CS or placebo $(3 \mathrm{ml})$ were administered as previously described at 30 -min intervals. After the 90-min drug administration period, alveolar hypoxia was induced for $15 \mathrm{~min}$. Cardiovascular measurements were recorded $15 \mathrm{~min}$ after each aerosol treatment, at the end of hypoxia, and 30 min after recovery. Arterial blood gas samples were obtained at baseline, after each aerosol treatment, after $15 \mathrm{~min}$ of hypoxia, and after $30 \mathrm{~min}$ of recovery. Each animal was studied twice, once after treatment with placebo and once after treatment with CS, separated by a $24-\mathrm{h}$ period.

Data are expressed as mean \pm 1 SD. A one-way analysis of variance for repeated measures was used to compare within treatment group measurements to determine if pretreatment with CS altered the cardiovascular response to hypoxia and to determine if the cardiovascular response to alveolar hypoxia changed with repeated exposure to hypoxia (14). Separate analyses were performed for each set of experiments. Data points included in the analysis were baseline and postaerosol values, measurements after each 15-min epoch of hypoxia and each 30-min recovery period. If a significant difference was found, a Newman-Keuls multiple range test was performed to determine which means were statistically different. Significance was assigned at $p=0.05$ for all statistical tests.

\section{RESULTS}

Changes in arterial blood gases and $\mathrm{pH}$ during the single dose aerosol study are summarized in Table 1 . Both the control and CS groups exhibited a significant decrease in $\mathrm{PaO}_{2}$ from baseline during hypoxia. Arterial $\mathrm{pH}$ and $\mathrm{PaCO}_{2}$ were not altered after aerosol delivery of either compound or during any of the hypoxia epochs. Blood gas values followed an identical pattern in the triple dose aerosol study with only the $\mathrm{PaO}_{2}$ changing significantly during hypoxia (Table 2 ).

The hemodynamic changes that occurred during the single dose aerosol study are summarized in Table 3. Pulmonary arterial pressure rose significantly $(p<0.05)$ during all hypoxia epochs after both placebo and CS aerosols (31 and 35\% during

Table 1. Arterial blood gases and pH during alveolar normoxia and hypoxia epochs after single dose of CS or saline*

\begin{tabular}{lcccc}
\hline & Baseline & Postaerosol & Hypoxia 1 & Hypoxia 4 \\
\hline Saline control & & & & \\
$\mathrm{pH}$ & $7.42 \pm 0.06$ & $7.39 \pm 0.05$ & $7.40 \pm 0.08$ & $7.40 \pm 0.04$ \\
$\mathrm{PaO}_{2}$ & $72 \pm 10$ & $73 \pm 9$ & $37 \pm 10 \dagger$ & $35 \pm 13 \dagger$ \\
$\mathrm{PaCO}_{2}$ & $43 \pm 6$ & $46 \pm 5$ & $47 \pm 6$ & $46 \pm 6$ \\
$\mathrm{Cromolyn}$ sodium & & & & \\
$\mathrm{pH}$ & $7.44 \pm 0.04$ & $7.41 \pm 0.03$ & $7.39 \pm 0.06$ & $7.42 \pm 0.07$ \\
$\mathrm{PaO}_{2}$ & $69 \pm 13$ & $73 \pm 9$ & $32 \pm 9 \dagger$ & $34 \pm 11 \dagger$ \\
$\mathrm{PaCO}_{2}$ & $45 \pm 5$ & $47 \pm 5$ & $46 \pm 6$ & $43 \pm 6$ \\
\hline
\end{tabular}

* Data are means \pm 1 SD for $n=8$ and are corrected to the animal's body temperature.

$\dagger p<0.05$ from baseline. 
the 1 st epoch and 37 and $32 \%$ during the 4 th epoch, respectively). Pulmonary vascular resistance also increased significantly from baseline $(p<0.05)$ during all epochs of hypoxia after both placebo and CS aerosols (58 and $42 \%$ during the 1st epoch and 75 and $42 \%$ during the 4 th epoch, respectively:). No significant differences were detected in either the pulmonary vascular response to hypoxia between control and CS groups or between

Table 2. Arterial blood gases and $p H$ during alveolar normoxia and hypoxia after triple dose of CS or saline*

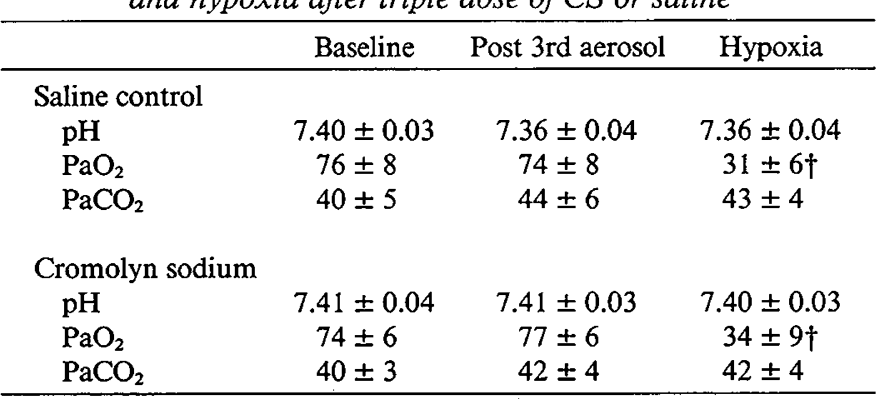

* Data are means \pm 1 SD for $n=8$ and are corrected to the animal's body temperature.

$\dagger p<0.05$ from baseline. hypoxia epochs within the same group. Other cardiovascular variables were not significantly altered during the study.

Hemodynamic alterations during the triple dose study are summarized in Table 4. Pulmonary arterial pressure increased $53 \%$ from baseline during hypoxia $(p<0.01)$ after placebo treatment and only $13 \%$ after CS treatment. Pulmonary vascular resistance increased from baseline during hypoxia after placebo $(p<0.05)$, but did not change significantly after CS. The increase in pulmonary vascular resistance during hypoxia after placebo was more $(101 \%)$ than that after $\operatorname{CS}(32 \% ; p<0.005$ comparing mean values). No other cardiovascular variables were significantly altered during the study.

Figure 1 illustrates the changes in pulmonary arterial pressure and pulmonary vascular resistance during alveolar hypoxia in both the single and triple dose studies. No difference was detected in the response after a single $(30 \mathrm{mg})$ dose of CS, but the pulmonary vascular response to hypoxia was blunted after three 30 -mg doses of CS. Although there appears to be enhancement of hypoxic pulmonary vasoconstriction between the 1st and 4th hypoxia epochs during the single dose study, the difference was not statistically significant.

During all hypoxia epochs in the single dose study, pulmonary vascular changes occurred within $1 \mathrm{~min}$ of the onset of hypoxia and were sustained throughout the 15-min experimental period. Hemodynamic measurements rapidly returned to baseline levels

Table 3. Hemodynamic variables during alveolar normoxia and hypoxia epochs after single dose of CS or normal saline*

\begin{tabular}{|c|c|c|c|c|c|c|}
\hline & \multicolumn{3}{|c|}{ Normal saline } & \multicolumn{3}{|c|}{$\mathrm{CS}$} \\
\hline Cardiac output $\left(\mathrm{ml} \cdot \mathrm{kg}^{-1} \cdot \mathrm{min}^{-1}\right)$ & $299 \pm 62$ & $289 \pm 65$ & $277 \pm 33$ & $270 \pm 65$ & $274 \pm 67$ & $295 \pm 64$ \\
\hline Stroke volume $\left(\mathrm{ml} \cdot \mathrm{kg}^{-1}\right)$ & $1.5 \pm 0.2$ & $1.2 \pm 0.3$ & $1.2 \pm 0.3$ & $1.3 \pm 0.3$ & $1.1 \pm 0.3$ & $1.1 \pm 0.2$ \\
\hline $\begin{array}{l}\text { Pulmonary arterial pressure (mm } \\
\mathrm{Hg} \text { ) }\end{array}$ & $22 \pm 3$ & $27 \pm 5 \dagger$ & $29 \pm 5 \dagger$ & $23 \pm 4$ & $30 \pm 4 \dagger$ & $30 \pm 5 \dagger$ \\
\hline $\begin{array}{l}\text { Systemic arterial pressure (mm } \\
\mathrm{Hg} \text { ) }\end{array}$ & $74 \pm 8$ & $71 \pm 8$ & $68 \pm 9$ & $75 \pm 6$ & $75 \pm 6$ & $71 \pm 8$ \\
\hline $\begin{array}{l}\text { Systemic vascular resistance (mm } \\
\left.\mathrm{Hg} \cdot \mathrm{liter}^{-1} \cdot \mathrm{kg}^{-1} \cdot \mathrm{min}^{-1}\right)\end{array}$ & $255 \pm 58$ & $257 \pm 58$ & $251 \pm 52$ & $280 \pm 50$ & $282 \pm 65$ & $267 \pm 68$ \\
\hline
\end{tabular}

*Data are mean $\pm 1 \mathrm{SD} ; n=8 ;$ hypoxia $=8 \% \mathrm{O}_{2}, 5 \% \mathrm{CO}_{2}, 87 \% \mathrm{~N}_{2}$.

$\dagger p<0.05$ from baseline.

Table 4. Hemodynamic variables during alveolar normoxia and hypoxia after triple dose of CS or normal saline*

\begin{tabular}{|c|c|c|c|c|c|c|}
\hline & \multicolumn{3}{|c|}{ Normal saline } & \multicolumn{3}{|c|}{$\mathrm{CS}$} \\
\hline & Baseline & Post 3 rd aerosol & Hypoxia & Baseline & Post 3rd aerosol & Hypoxia \\
\hline Cardiac output $\left(\mathrm{ml} \cdot \mathrm{kg}^{-1} \cdot \mathrm{min}^{-1}\right)$ & $252 \pm 52$ & $252 \pm 60$ & $261 \pm 48$ & $246 \pm 56$ & $231 \pm 57$ & $254 \pm 71$ \\
\hline Heart rate $(\mathrm{bpm})$ & $199 \pm 29$ & $187 \pm 31$ & $237 \pm 39$ & $193 \pm 41$ & $200 \pm 28$ & $227 \pm 22$ \\
\hline Stroke volume $\left(\mathrm{ml} \cdot \mathrm{kg}^{-1}\right)$ & $1.3 \pm 0.3$ & $1.3 \pm 0.3$ & $1.1 \pm 0.3$ & $1.4 \pm 0.5$ & $1.2 \pm 0.2$ & $1.2 \pm 0.3$ \\
\hline $\begin{array}{l}\text { Pulmonary arterial pressure } \\
(\mathrm{mm} \mathrm{Hg})\end{array}$ & $20 \pm 7$ & $21 \pm 9$ & $29 \pm 8 * \dagger \ddagger$ & $22 \pm 6$ & $20 \pm 7$ & $24 \pm 5$ \\
\hline Left atrial pressure $(\mathrm{mm} \mathrm{Hg})$ & $6 \pm 2$ & $5 \pm 2$ & $5 \pm 2$ & $7 \pm 2$ & $6 \pm 3$ & $6 \pm 3$ \\
\hline $\begin{array}{l}\text { Pulmonary vascular resistance } \\
\left(\mathrm{mm} \mathrm{Hg} \cdot \mathrm{liter}^{-1} \cdot \mathrm{kg}^{-1} \cdot \mathrm{min}^{-1}\right)\end{array}$ & $66 \pm 41$ & $64 \pm 41$ & $106 \pm 46 \S \|$ & $60 \pm 19$ & $61 \pm 29$ & $73 \pm 25$ \\
\hline $\begin{array}{l}\text { Systemic arterial pressure (mm } \\
\mathrm{Hg})\end{array}$ & $74 \pm 8$ & $75 \pm 9$ & $64 \pm 11$ & $72 \pm 9$ & $73 \pm 11$ & $68 \pm 12$ \\
\hline $\begin{array}{l}\text { Systemic vascular resistance } \\
\left(\mathrm{mm} \mathrm{Hg} \cdot \mathrm{liter}^{-1} \cdot \mathrm{kg}^{-1} \cdot \mathrm{min}^{-1}\right)\end{array}$ & $304 \pm 71$ & $311 \pm 83$ & $250 \pm 38$ & $321 \pm 120$ & $342 \pm 120$ & $285 \pm 111$ \\
\hline
\end{tabular}

$*$ Data are means $\pm 1 \mathrm{SD} ; n=8 ;$ hypoxia $=8 \% \mathrm{O}_{2}, 5 \% \mathrm{CO}_{2}, 87 \% \mathrm{~N}_{2}$

$\dagger p<0.01$ from baseline.

$\ddagger p<0.05$ from CS during hypoxia.

$\S p<0.05$ from baseline.

$\| p<0.01$ from CS during hypoxia. 
during the recovery periods. The administration of CS did not alter the time course of the changes during hypoxia. Figure 2 illustrates the timing of these changes in pulmonary and systemic arterial pressure and pulmonary blood flow in one lamb. Interestingly, return of pulmonary arterial pressure toward baseline appears to be delayed during recovery after CS in this animal, but this observation was not a consistent finding. During the triple dose study, CS blunted the initial rise in pulmonary arterial pressure during hypoxia, a finding that was sustained throughout the epoch (Table 5). Because of interanimal variability, the calculated pulmonary vascular resistance during hypoxia after placebo did not become statistically significant until the $10-\mathrm{min}$ measurement.
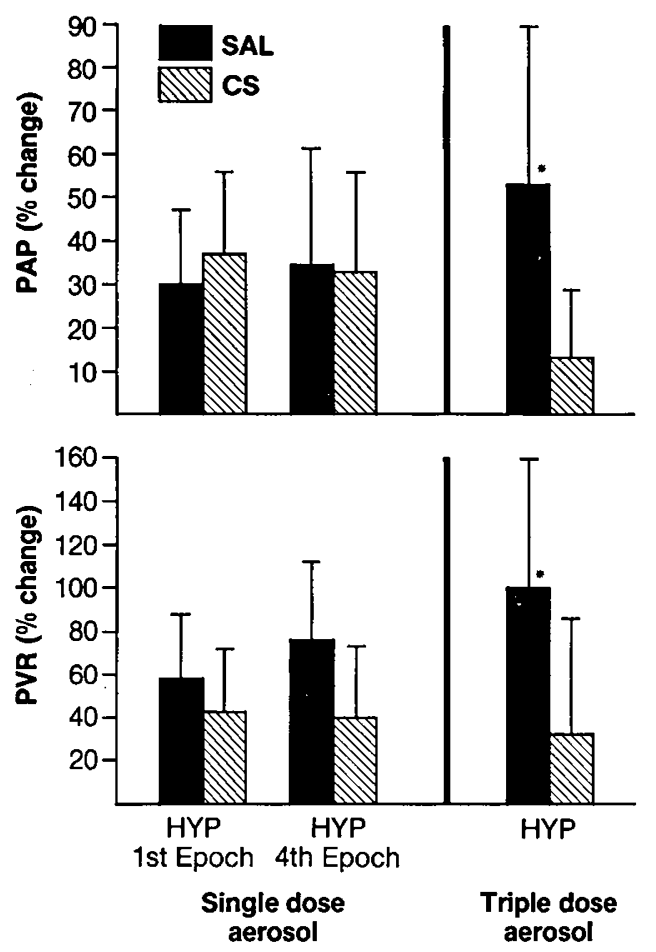

Fig. 1. Percent change in pulmonary arterial pressure $(P A P)$ and pulmonary vascular resistance $(P V R)$ from baseline $\left(\mathrm{FIO}_{2} 0.21\right)$, during hypoxia after normal saline ( $S A L)$ and CS aerosols in both the single (30 mg CS) $(n=8)$ and triple (90 mg CS) $(n=8)$ dose studies. Significant differences in PAP $(p<0.05)$ and PVR $(p<0.005)$ within groups are denoted by an asterisk.

\section{DISCUSSION}

Our results provide evidence that aerosolized CS blunts the pulmonary vascular response to alveolar hypoxia. A single dose of aerosolized CS $(30 \mathrm{mg})$ did not alter HPV, whereas a triple dose $(90 \mathrm{mg}$ ) given over a 90 -min period attenuated the rise in pulmonary arterial pressure and resistance that was seen during hypoxia after placebo treatment.

We also examined the influence of repeated closely spaced epochs of alveolar hypoxia on the intensity of pulmonary vasoconstriction. Previous studies have reported both enhancement of (15) or no effect on (16) the HPV response with repetition of hypoxic challenges in adult animals. Our findings indicate that four consecutive challenges with alveolar hypoxia did not alter the observed pulmonary vascular changes in conscious newborn lambs, and suggest that the mechanisms responsible for HPV do not change or fatigue with rapidly repeated stimulation.

We previously showed that CS administered as an intravenous infusion blocked the pulmonary vascular response to hypoxia in lambs, noting a $3 \%$ decrease in pulmonary vascular resistance during hypoxia compared to a $57 \%$ increase with placebo (12). The animals in our previous study received an intravenous loading dose of $24 \mathrm{mg} / \mathrm{kg}$ of CS before the onset of hypoxia followed by an additional $45 \mathrm{mg} / \mathrm{kg}$ during hypoxia. In contrast, during our current studies, each lamb was administered only 4$5 \mathrm{mg} / \mathrm{kg} \mathrm{CS}$ in the single dose study and $12-15 \mathrm{mg} / \mathrm{kg}$ in the triple dose study. Ahmed et al. (13) administered $20 \mathrm{mg} / \mathrm{kg}$ of aerosolized CS to their animals and noted a $42 \%$ increase in pulmonary arterial pressure (compared to $68 \%$ during hypoxia alone) and a $27 \%$ increase in pulmonary vascular resistance (compared to $89 \%$ during hypoxia alone). Our findings after the triple dose study are similar to these previously reported observations that used a similar total dose administered as one treatment (13).

Estimates of actual CS delivery into the airways during inhalation studies vary from $5-14 \%$ of the total aerosolized dose (13, $17,18)$. Our study design allowed us to minimize loss of drug via swallowing by delivering the drug directly into the tracheostomy tube. Ultrasonic nebulizers similar to the type we used generate particles of $1-3 \mu \mathrm{m}$ mass median diameter, a size appropriate for lower respiratory tract deposition $(19,20)$. The fraction of the CS dose lost due to exhalation of the aerosol could not be quantified, thereby precluding precise calculation of the dose deposited in the airways. However, a substantial amount of the administered CS dose was likely deposited throughout the tracheobronchial tree.

There are no data to describe adequately the kinetics of CS in newborn animals or humans. The apparent pharmacodynamic difference in the aerosol versus intravenous doses for CS may be

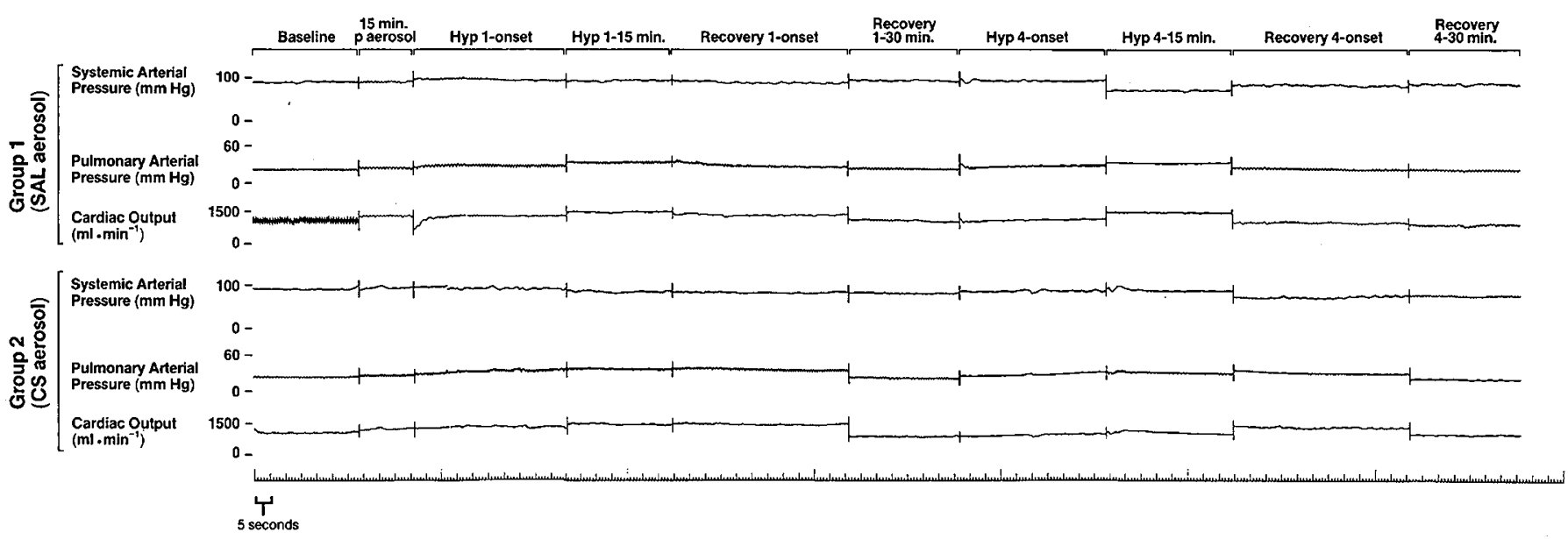

Fig. 2. Actual hemodynamic changes in systemic and pulmonary arterial pressures and cardiac output from baseline in one lamb after normal saline (SAL) and CS aerosols during the first and fourth hypoxia epochs (HYP 1 and HYP 4) and recovery periods of the single dose CS study. 
Table 5. Hemodynamic variables throughout epoch of alveolar hypoxia after triple dose of CS or normal saline*

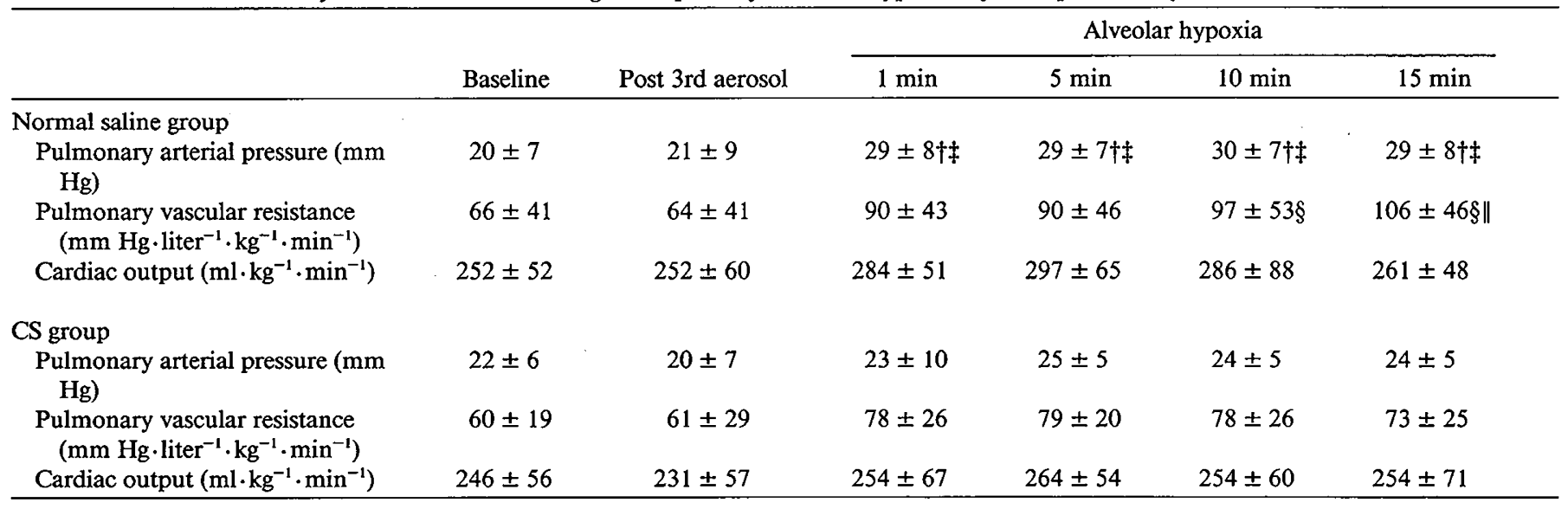

* Data are means $\pm 1 \mathrm{SD} ; n=8$; hypoxia $=8 \% \mathrm{O}_{2}, 5 \% \mathrm{CO}_{2}, 87 \% \mathrm{~N}_{2}$.

$\dagger p<0.01$ from baseline.

$\ddagger p<0.05$ from CS during hypoxia.

$\S p<0.05$ from baseline.

$\| p<0.01$ from CS during hypoxia.

partially explained by "site-specific" activity found in adults (21) which is enhanced by local administration via the aerosol route. To examine this phenomenon, we performed pharmacokinetic modeling (22) on previously published mean serum concentration data for CS after inhalation (17). This demonstrated an absorption rate constant after inhaled CS that was greater than the elimination rate constant after intravenous administration and a distribution rate constant after inhalation that was less than that after intravenous administration. These findings suggest that, at least in adults, distribution is the rate-limiting determinant for pharmacologic activity of inhaled CS. Because the residence time of the drug in the peribronchial/perivascular tissues after inhalation would be increased over that expected after intravenous administration, aerosol delivery of CS would place the drug at its primary site of action and result in prolonged residence at that site because of its slow distribution.

CS may have pharmacologic effects other than stabilization of mast cell membranes as it has been shown to exert direct effects on bronchial smooth muscle (23) and to inhibit reflex-induced bronchoconstriction in dogs, most likely by suppressing lung irritant receptors (24). It has also been shown to inhibit the inflammatory effects of platelet-activating factor, a known bronchoconstrictor and vasoconstrictor, by a mechanism independent of mast cell activity (25). All of these effects can be explained by the ability of CS to inhibit calcium influx into cells, a process also necessary for mast cell degranulation $(21,23)$. CS does not possess any antihistaminic, $\alpha$-blocking, or catecholamine-releasing properties (4). It also has no antagonistic activity against prostaglandins or leukotrienes in isolated tissue or anesthetized guinea pigs (26).

Two recent reports have refuted the efficacy of parenteral CS as a modifier of HPV $(27,28)$. A study performed in hypoxic human volunteers after intravenous infusion of CS reported that a smaller dose than that used in our intravenous study did not block HPV, but the infusion did cause facial flushing and headache (27), systemic symptoms that have been previously reported in humans (18). Mean systemic pressure and cardiac index were not affected by CS infusion. Another recent study (28) has been performed in newborn and young lambs under conditions similar to our intravenous CS study. Alveolar hypoxia was acutely induced after administration of CS for $10 \mathrm{~min}$, and no significant differences were noted in the rise in pulmonary arterial pressure during hypoxia after CS compared to placebo. The magnitude of rise (from mean values) in pulmonary arterial pressure during hypoxia was, however, less after CS compared to controls in both newborn (38 versus $68 \%$ in controls) and young (40 versus $55 \%$ in controls) lambs. The differences noted in these two studies when compared to our own data and other published studies emphasize the need for continuing investigation of the mechanisms responsible for HPV and the influence of CS on HPV.

The effects of CS on the pulmonary circulation have not been satisfactorily explained. Results from this study and our previous work (12), as well as studies in adult sheep $(4,13)$, dogs $(10,11)$, and rats (3) suggest that CS alters the sequence of events that leads to HPV. Additionally, the efficacy of lower doses of aerosolized CS in attenuating the physiologic response to HPV support a local site of action for the drug similar to that postulated for its local action in the treatment of asthma (21). The mechanism of action of CS, the concentration-effect relationships of the drug, and the contribution of mast cell degranulation to HPV remain to be elucidated.

Acknowledgments. The authors acknowledge the excellent technical assistance of Mr. Thomas Sziszak, Mr. Robert Walker, and Ms. Teresa Trammell, and thank Dr. Robert Warren for his advice and support during this project, and Fison's Corp. for donating the CS.

\section{REFERENCES}

1. Fishman AP 1976 Hypoxia on the pulmonary circulation. How and where it acts. Circ Res 38:221-231

2. Grover RF, Wagner WW, McMurtry IF and Reeves JT 1983 Pulmonary circulation. In: Shepherd JT, Abboud FM (eds) Handbook of Physiology, The Cardiovascular System, Vol III, Pt 2. American Physiological Society, Bethesda, MD, pp 103-136

3. Haas F, Bergofsky EH 1972 Role of the mast cell in the pulmonary pressor response to hypoxia. J Clin Invest 51:3154-3162

4. Ahmed T, Oliver W, Frank B, Robinson M, Wanner A 1982 Hypoxic pulmonary vasoconstriction in conscious sheep: role of mast cell degranulation. Am Rev Respir Dis 126:291-297

5. Martin LF, Tucker A, Munroe ML, Reeves JT 1978 Lung mast cells and hypoxic pulmonary vasoconstriction in cats. Respiration 35:73-77

6. Zhu YJ, Kradin R, Brandstetter RD, Staton G, Moss J, Hales CA 1983 Hypoxic pulmonary hypertension in the mast cell-deficient mouse. $J$ Appl Physiol 54:680-686

7. Mungall IPF 1976 Hypoxia and lung mast cells: influence of disodium cromoglycate. Thorax 31:94-100

8. Tucker A, McMurtry IF, Alexander AF, Reeves JT, Grover RF 1977 Lung mast cell density and distribution in chronically hypoxic animals. $\mathrm{J}$ Appl Physiol 42:174-178

9. Schwartz LB, Austen KF 1984 Structure and function of the chemical mediators of mast cells. Prog Allergy 34:271-321

10. Rengo F, Trimarco B, Ricciardelli B, Volpe M, Violini R, Sacca L, Chiariello M 1979 Effects of disodium cromoglycate on hypoxic pulmonary hypertension in dogs. $\mathrm{J}$ Pharmacol Exp Ther 211:686-689

11. Naeije R, Leeman M, Lejeune P 1986 Effects of diethylcarbamazine and 
cromolyn sodium on hypoxic pulmonary vasoconstriction in dogs. Bull Eur Physiolpathol Respir 22:75-80

12. Taylor BJ, Fewell JE, Kearns GL, Hill DE 1986 Cromolyn sodium decreases the pulmonary vascular response to alveolar hypoxia in lambs. Pediatr Res 20:834-837

13. Ahmed T, Oliver W, Marchette B 1986 Modification of hypoxic pulmonary vasoconstriction by aerosolized cromolyn sodium. Bull Eur Physiopathol Respir 22:61-64

14. Winer BJ 1962 Single-factor experiments having repeated measures on the same elements. In: Statistical Principles in Experimental Design. McGrawHill Book Company, New York, pp 261-308

15. Unger M, Atkins M, Briscoe WA, King TKC 1977 Potentiation of pulmonary vasoconstrictor response with repeated intermittent hypoxia. J Appl Physiol 43:662-667

16. Miller MA, Hales CA 1980 Stability of alveolar hypoxic vasoconstriction with intermittent hypoxia. J Appl Physiol 49:846-850

17. Neale MG, Brown K, Hodder RW, Auty RM 1986 The pharmacokinetics of sodium cromoglycate in man after intravenous and inhalation administration. Br J Clin Pharmacol 22:373-382

18. Walker SR, Evans ME, Richards AJ, Paterson JW 1972 The fate of [14C] disodium cromoglycate in man. J Pharm Pharmacol 24:525-531

19. Hiller FC, Mazumder MK, Wilson JD, Wilson FC, Bone RC 1983 Aerodynamic size distribution of therapeutic aerosols. Aerosol Sci Technol 2:298(abstr)

20. Lippmann M 1977 Regional deposition of particles in the human respiratory tract. In: Lee DHK (ed) Handbook of Physiol. Reactions of Environmental Agents. American Physiological Society, Bethesda, MD, pp 213-232

21. Brogden RN, Speight TM, Avery GS 1974 Sodium cromoglycate (cromolyn sodium): a review of its mode of action, pharmacology, therapeutic efficacy and use. Drugs 7:164-182

22. Sheiner LB, Beal SL 1985 Pharmacokinetic parameter estimates from several least squares procedures: superiority of extended least squares. J Pharmacokinet Biopharm 13:185-201

23. Kunkel G, Baumer FE, Okuda M, van Cauwenberge $P 1985$ Mode of action and indication for disodium cromoglycate (DSCG). Allerg Immunopathol 13:285-289

24. Richards IM, Dixon M, Jackson DM, Vendy K 1986 Alternative modes of action of sodium cromoglycate. Agents Actions 18:294-300

25. Basran GS, Page CP, Paul W, Morley J 1983 Cromoglycate (DSCG) inhibits responses to platelet-activating factor (paf-acether) in man: an alternative mode of action for DSCG in asthma? Eur J Pharmacol 86:143-144

26. Cox JSG, Beach JE, Blair AMJN, Clark AJ, King J, Lee TB, Loveday DEE, Moss GF, Orr TSC, Ritchie JT, Sheard P 1970 Disodium cromoglycate (Intal). Adv Drug Res 5:115

27. Hallemans R, Malot C, Naeije R, Dechamps P, Cailleau S 1986 Cromolyn sodium does not inhibit hypoxic pulmonary vasoconstriction in normal man. Chest 89:461S(abstr)

28. Frantz EG, Schreiber MD, Heymann MA, Soifer SJ 1986 Cromolyn sodium fails to prevent hypoxia-induced pulmonary vasoconstriction in newborn and young lambs. Pediatr Res 20:429A(abstr) 